Article

\title{
Development of Embedded EM Sensors for Estimating Tensile Forces of PSC Girder Bridges
}

\author{
Junkyeong Kim ${ }^{1}$ (D) , Ju-Won Kim ${ }^{2}$, Chaggil Lee ${ }^{1}$ and Seunghee Park ${ }^{2, *}$ \\ 1 Department of Civil \& Environmental System Engineering, Sungkyunkwan University 2066, Seobu-ro, \\ Jangan-gu, Suwon-si, Gyonggi-do 16419, Korea; junk135@nate.com (J.K.); tolck81@gmail.com (C.L.) \\ 2 School of Civil \& Architectural Engineering, Sungkyunkwan University 2066, Seobu-ro, Jangan-gu, \\ Suwon-si, Gyonggi-do 16419, Korea; malsi@nate.com \\ * Correspondence; shparkpc@skku.edu; Tel.: +82-031-290-7525
}

Received: 21 July 2017; Accepted: 28 August 2017; Published: 30 August 2017

\begin{abstract}
The tensile force of pre-stressed concrete (PSC) girders is the most important factor for managing the stability of PSC bridges. The tensile force is induced using pre-stressing (PS) tendons of a PSC girder. Because the PS tendons are located inside of the PSC girder, the tensile force cannot be measured after construction using conventional NDT (non-destructive testing) methods. To monitor the induced tensile force of a PSC girder, an embedded EM (elasto-magnetic) sensor was proposed in this study. The PS tendons are made of carbon steel, a ferromagnetic material. The magnetic properties of the ferromagnetic specimen are changed according to the induced magnetic field, temperature, and induced stress. Thus, the tensile force of PS tendons can be estimated by measuring their magnetic properties. The EM sensor can measure the magnetic properties of ferromagnetic materials in the form of a B (magnetic density)-H (magnetic force) loop. To measure the B-H loop of a PS tendon in a PSC girder, the EM sensor should be embedded into the PSC girder. The proposed embedded EM sensor can be embedded into a PSC girder as a sheath joint by designing screw threads to connect with the sheath. To confirm the proposed embedded EM sensors, the experimental study was performed using a down-scaled PSC girder model. Two specimens were constructed with embedded EM sensors, and three sensors were installed in each specimen. The embedded EM sensor could measure the B-H loop of PS tendons even if it was located inside concrete, and the area of the B-H loop was proportionally decreased according to the increase in tensile force. According to the results, the proposed method can be used to estimate the tensile force of unrevealed PS tendons.
\end{abstract}

Keywords: tensile force estimation; embedded EM sensor; PS Tendon; B-H loop measurement; PSC girder

\section{Introduction}

Recently, civil structures and their behaviors have become more complicated due to the development of materials, design, and construction technology. Also, the evaluation and maintenance of these structures have become very important. To inspect these structures, nondestructive tests (NDTs) have become a solution for evaluating structural health [1-7]. The main benefit of such non-destructive evaluation systems is that a structure does not need to be altered while being monitored. The condition of a structure can be assessed on site, while the information derived from a non-destructive evaluation can be instrumental in making engineering decisions concerning the fate of a structure. This ensures better judgment when determining whether or not a structure is safe, thus avoiding the construction, labor, and social costs of replacing a structure that actually does not require replacement. In addition, NDT techniques can be applied to new structures as part of a monitoring scheme, which leads to a better understanding of the behavior and performance during the construction and servicing of a structure. 
Since the first post-tensioned concrete bridge was built in 1936, many PSC (pre-stressing concrete) bridges have been constructed globally [8]. However, after the sudden collapse of a number of post-tensioned concrete bridges, it was found that the post-tension system has long-term risks, such as corrosion of tendons caused by ingress of water and chloride ions into partially grouted ducts $[9,10]$. The tensile forces in the pre-stressing strands can vary due to a variety of losses including instantaneous losses such as elastic shortening, friction, and anchorage set occurring at the time of transfer of the pre-stressing force, as well as time-dependent losses due to steel relaxation and the concrete creep and shrinkage that occur after transfer of the pre-stressing force and during the life of the member. Accordingly, the measurement of the tensile force in a tendon becomes very important for long-term maintenance of such bridges, as well as for the purpose of design [11-15].

Various NDT methods have been studied to estimate tensile forces of tendons or cables. In addition, field measurements have been carried out by attaching sensors, such as a strain measuring gauges (Tensmeg), directly to the outside of the strand, or indirectly, by sensing the strain near the strand using an electrical strain gauge and vibrating wire strain gauge (VWSG) installed in the concrete or on a rebar near the duct [16]. More recently, various NDT methods for measuring pre-stressing forces have been studied using methods based on guided stress waves [17,18], a system identification technique based on modal parameters [19], an impedance method applied to an anchorage plate [20], and use of the in-strand encapsulated fiber Bragg grating (FBG) sensor [21,22].

Especially, a magnetic sensor is a reliable method for stress estimation of steel specimens, due to its outstanding superiorities including corrosion resistance, actual-stress measurement, nondestructive monitoring, and long service life [23]. The elasto-magnetic (EM) sensor is usually applied to measure the stress of ferromagnetic members and it consists of a primary excitation coil and a secondary induction coil. It can measure the permeability to estimate the stress and it has been used to monitor the stress in exposed steel cables on field more than ten years [24-26]. The many types of EM sensors were invested using coil type [27], yoke-shaped electromagnet with hall sensors [28], and coil type electromagnet with magneto-electric-laminated composite sensor [23].

However, the previous magnetic sensors should located closely to specimen and it cannot be applied actual PSC girder that the PS (pre-stressing) tendons did not expose to outside of girder. To overcome this limitation, this research proposed an embedded EM sensor that can embed into the PSC girder and measure the magnetic responses of internal PS tendons to improve field applicability. For this purpose, embedded EM sensors are developed for measuring the magnetic hysteresis loop variations in pre-stressing tendons and a test was carried out using a $6 \mathrm{~m}$ down-scaled PSC girder beam in order to verify the proposed method.

\section{Development of the Embedded EM Sensor}

This study applied an EM sensor to estimate the tensile force of PS tendons. The EM sensor can measure the induced stress of ferromagnetic specimen by the elasto-magnetic effect [29]. The EM sensor should be located inside a PSC girder to measure the magnetic responses of the PS tendons because the tendons are built into the PSC girder and could not approach after casting concrete. To apply an EM sensor to an actual PSC girder, an embedded EM sensor was developed. The embedded EM sensor consists of a cylindrical bobbin with screw threads on both ends to connect with the sheath, a primary coil to generate a magnetic field, a secondary coil to measure the magnetic response of the PS tendon, and an external cover to protect the coils, as shown in Figure 1. The ends of the primary and secondary coils are connected to coaxial cables (Figure 2a), and a PVC (poly vinyl chloride) pipe is used as the external cover (Figure 2b) to protect the EM sensor from impact and water from the concrete. 


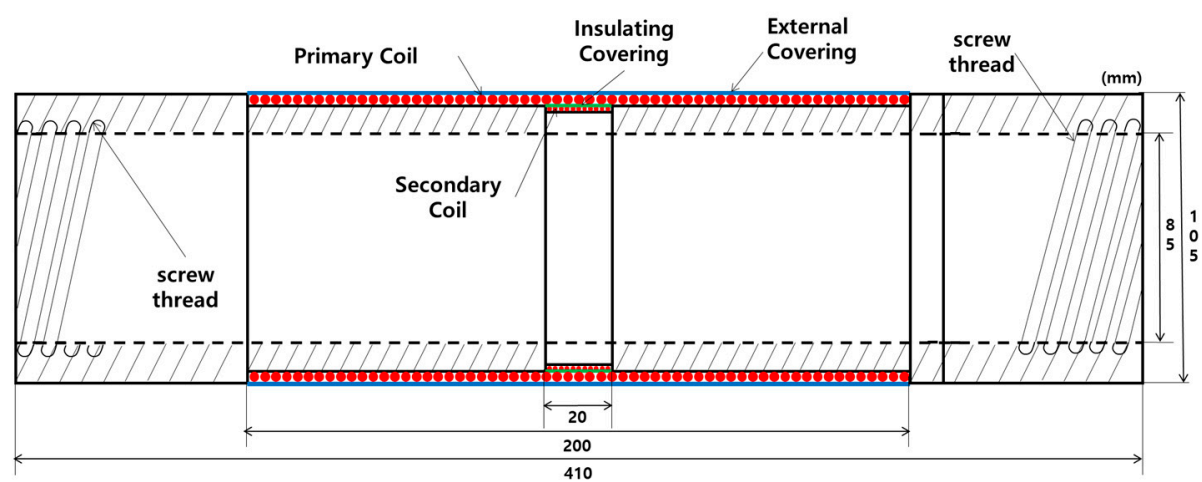

Figure 1. Schematic of the embedded EM sensor.

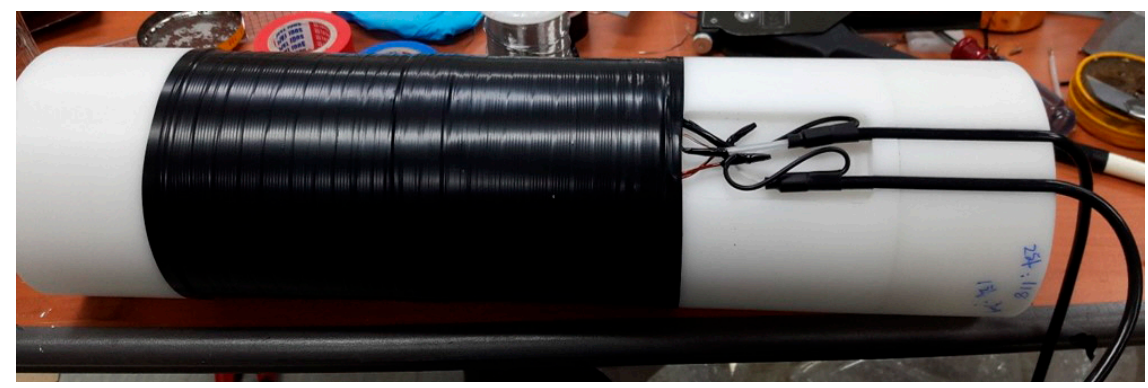

(a)

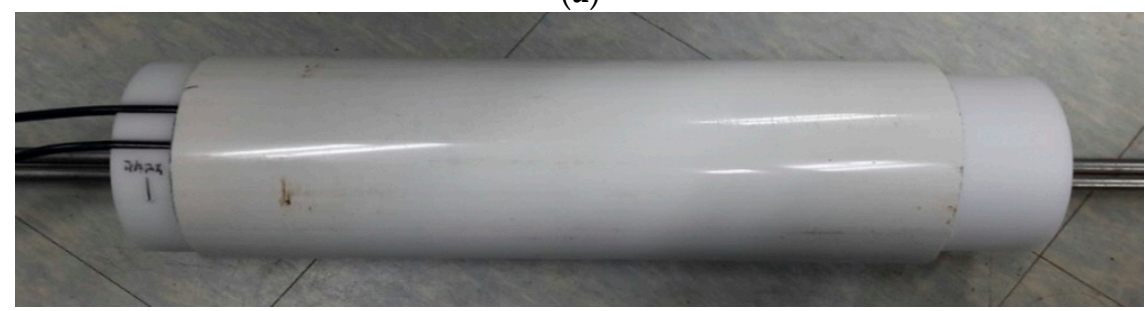

(b)

Figure 2. Embedded EM sensor. (a) Connection with coils and cable, (b) External protection cover.

The embedded EM sensor is installed between the sheaths as a sheath joint, as shown in Figure 3. Both sides of the EM sensor have screw threads, allowing the sensor to be installed at any position along the sheath line. Also, the joints are sealed using tape to prevent water permeation into the sheath.

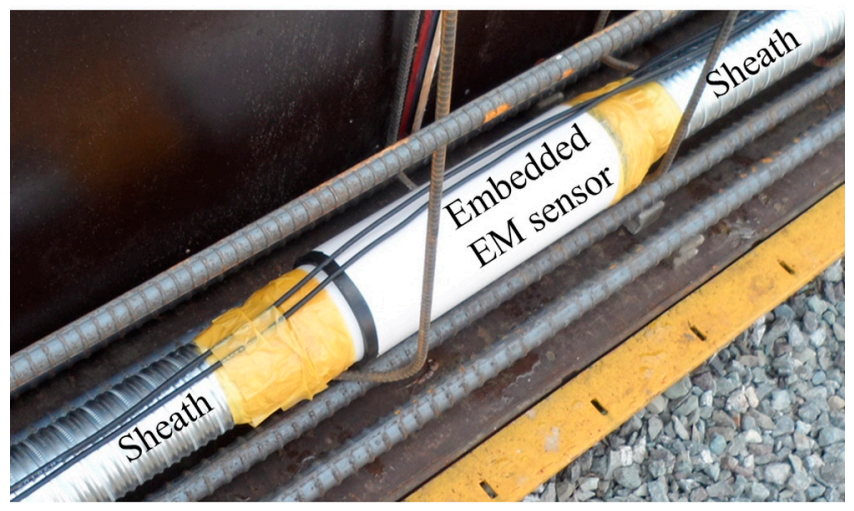

Figure 3. Installation of an embedded EM sensor. 


\section{Experimental Study}

\subsection{Experimental Setup and Test Procedure}

To confirm the proposed tensile force monitoring method, two down-scaled PSC girder specimens were constructed as shown in Figure 4. The span of the girders was $6 \mathrm{~m}$, and the height was $1 \mathrm{~m}$. The girders had 1 sheath line in each specimen (specimen 1 had a straight sheath, and specimen 2 had a curved sheath), and the embedded EM sensors were installed at the left and right anchorage parts and the maximum eccentric part as shown in Figures 4 and 5.

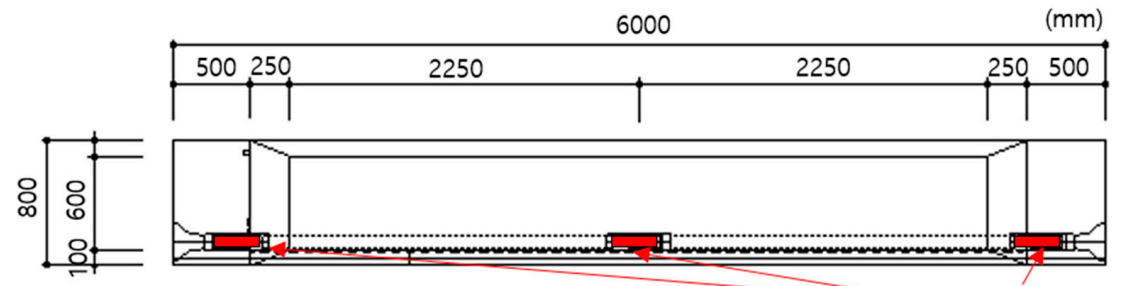

(a)

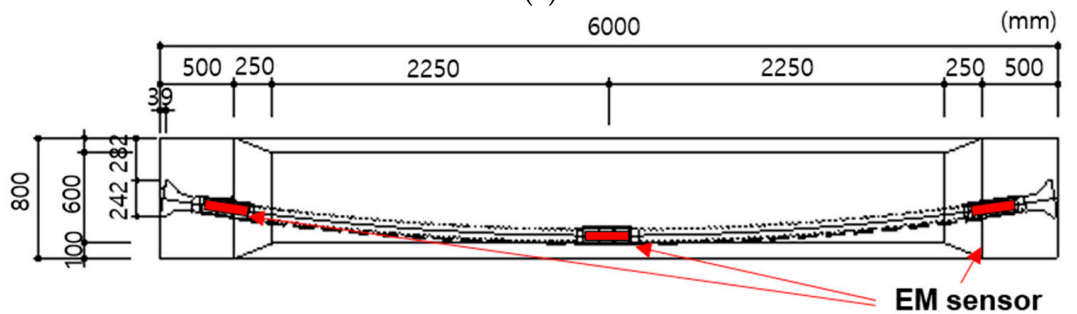

(b)

Figure 4. Schematic diagram of the test specimens. (a) Specimen 1: Straight sheath; (b) Specimen 2: Curved sheath.

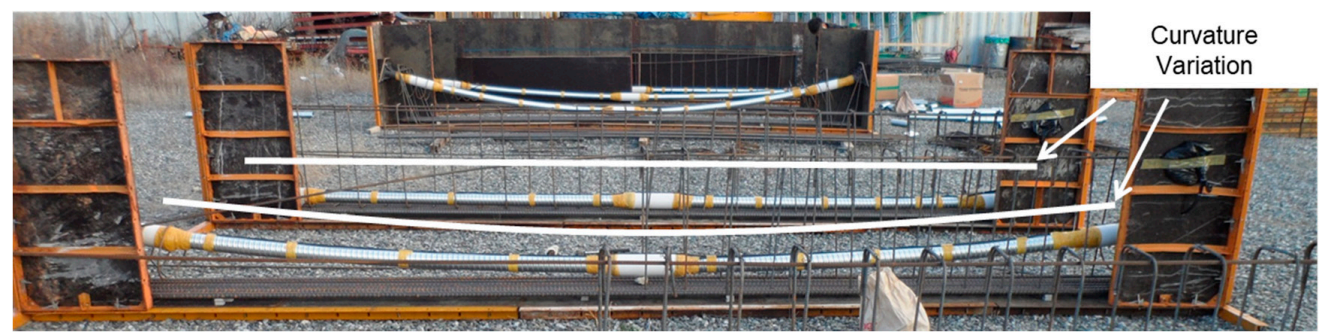

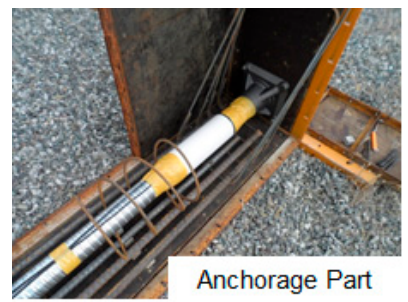

(b)

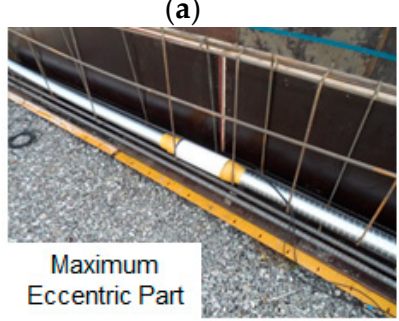

(c)

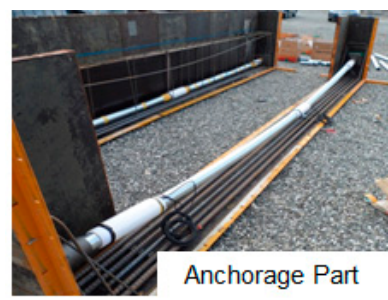

(d)

Figure 5. Installation of embedded EM sensors in a PSC girder. (a) EM sensor installed PSC girder, (b) Right anchorage part, (c) Maximum eccentric part, (d) Left anchorage part.

After installation of the EM sensors, the concrete was cast, and the PS tendons were arranged through the sheath lines. The nominal cross-section of each PS tendon was $158.8 \mathrm{~mm}$, and four PS tendons were placed in each sheath line. To measure the actual tensile force, a three-point load cell was installed as shown in Figure 6. 


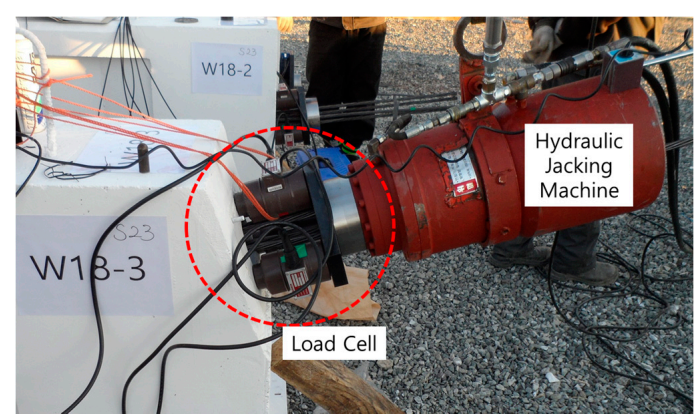

Figure 6. Installation of a load cell.

The tensile force on the PS tendons was induced by a multi-tendon hydraulic jacking machine. The jacking step was divided into 6 steps, and the details are listed in Table 1.

Table 1. Jacking steps of specimens.

\begin{tabular}{ccc}
\hline \multirow{2}{*}{ Jacking Step } & \multicolumn{2}{c}{ Tensile Force (kN) } \\
\cline { 2 - 3 } & Specimen 1 (Straight Sheath) & Specimen 2 (Curved Sheath) \\
\hline 1 & 0 & 0 \\
2 & 189 & 194 \\
3 & 272 & 275 \\
4 & 379 & 386 \\
5 & 486 & 492 \\
6 & 595 & 602 \\
\hline
\end{tabular}

\subsection{Results of EM Measurement}

The B-H loops of PS tendons were measured every jacking step using the embedded EM sensors. Figures 7 and 8 show the results of B-H loop measurement of specimens 1 and 2.

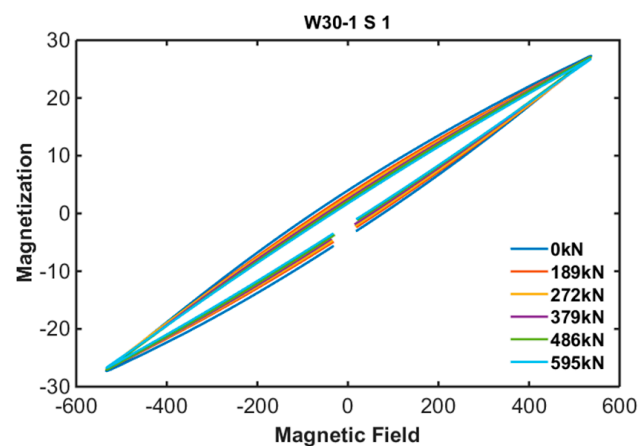

(a)

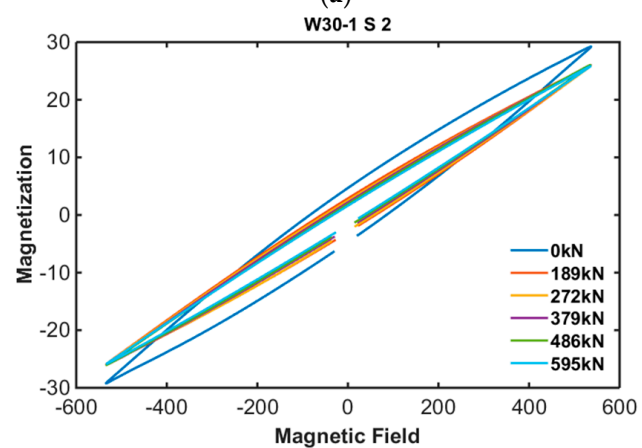

(b)

Figure 7. Cont. 


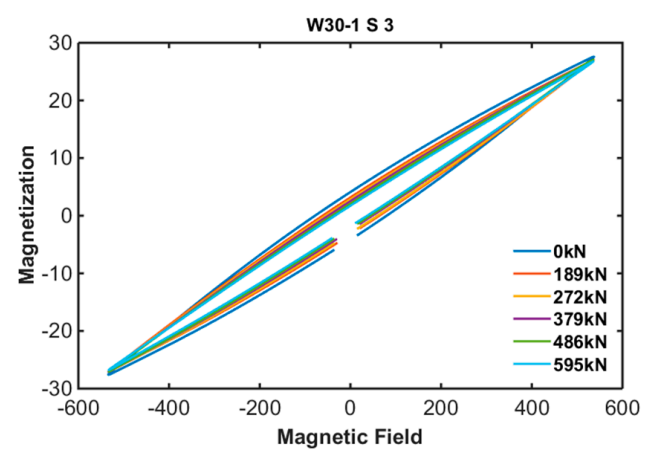

(c)

Figure 7. B-H loop of specimen 1: (a) Sensor no. 1-1; (b) Sensor no. 1-2; (c) Sensor no. 1-3.

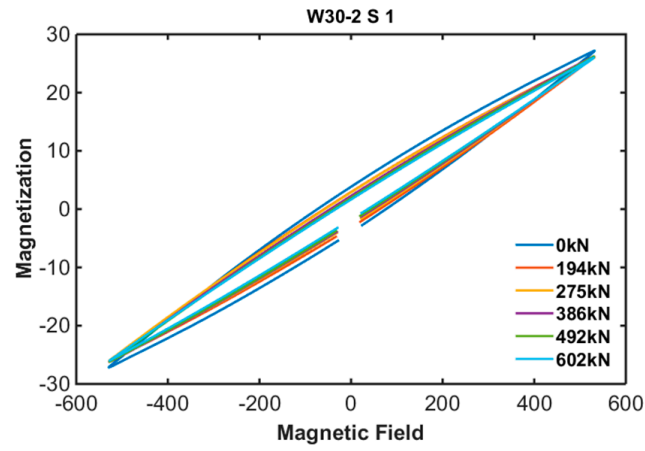

(a)

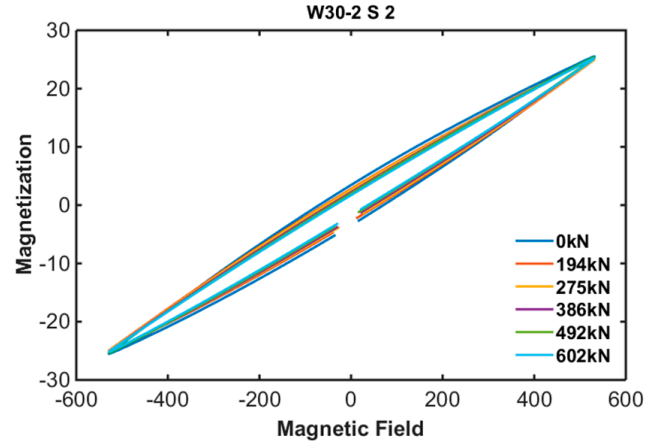

(b)

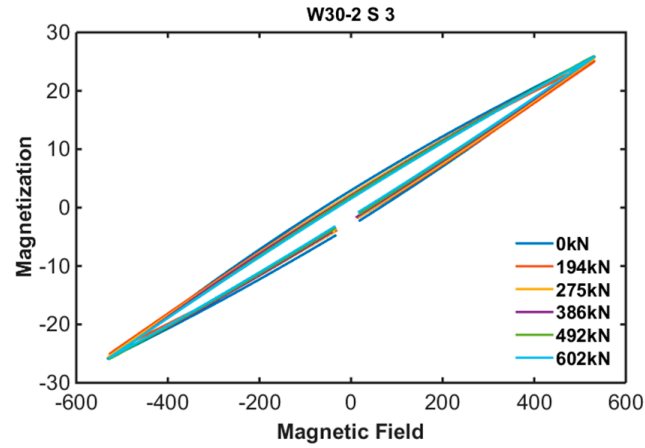

(c)

Figure 8. B-H loop of specimen 2: (a) Sensor no. 2-1; (b) Sensor no. 2-2; (c) Sensor no. 2-3.

According to the measurement results, proposed embedded EM sensor can measure the B-H loop of unrevealed PS tendon even if it located inside of concrete. 
To quantify the B-H loop variation due to induced tensile force, the area of the B-H loop was extracted. Figure 9 shows the variations in area of the B-H loop at each measurement of specimen 1. The results confirm that the area of the B-H loop decreased with increase in tensile force.

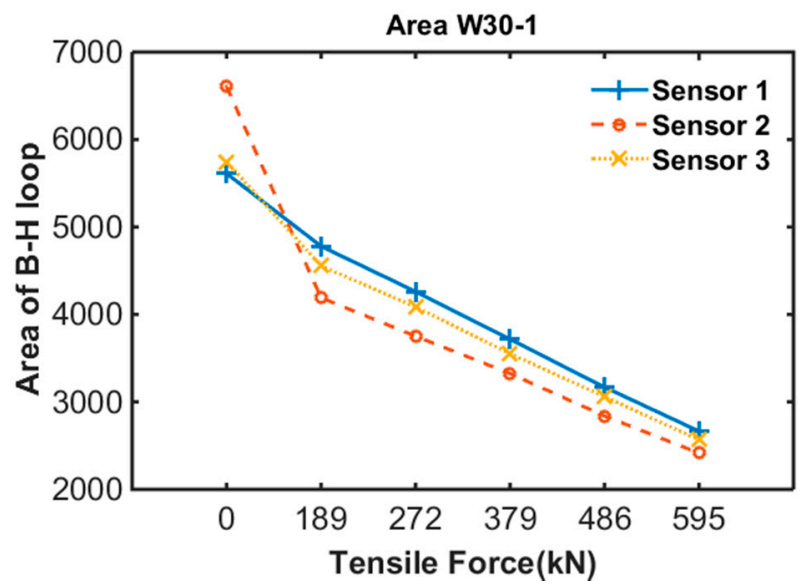

Figure 9. B-H loop of specimen 1.

Figure 10 shows the result of specimen 2. The results are similar to that of sheath no. 2; the area of the B-H loop decreased with increased tensile force.

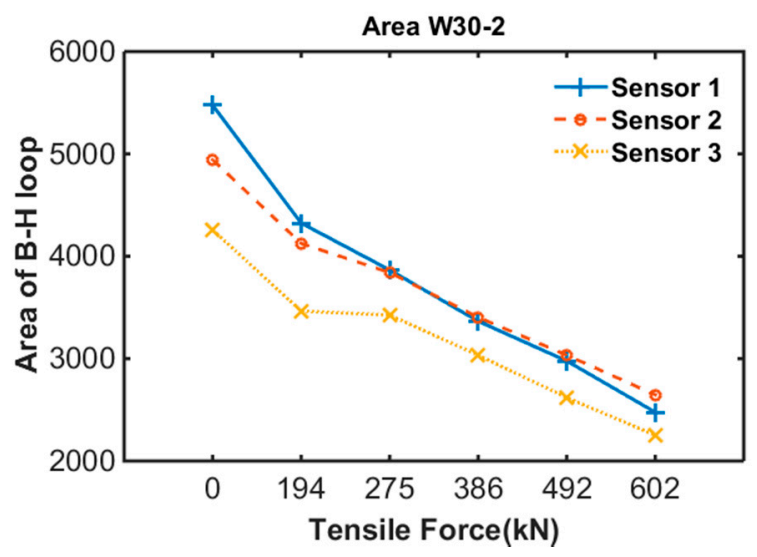

Figure 10. B-H loop of specimen 2.

To quantify the area variation due to tensile force, the area ratio was proposed as follows:

$$
A_{r}=\frac{A_{i}-A_{c}}{A_{i}}
$$

where $A_{i}$ is the measured area of the B-H loop at a tensile force of 0 (step 1 of each specimen) and $A_{c}$ is the measured area of the B-H loop at the current step.

Figure 11 shows the area ratio results of specimen 1 . The area ratio increased with an increase in tensile force. The area ratio of Sensor no. 1-2 was larger than those of Sensor no. 1-1 and 1-3, indicating that the tensile force was concentrated at the center of the PS tendon. It caused by the sheath of specimen 1 was straight and there was no friction loss. 


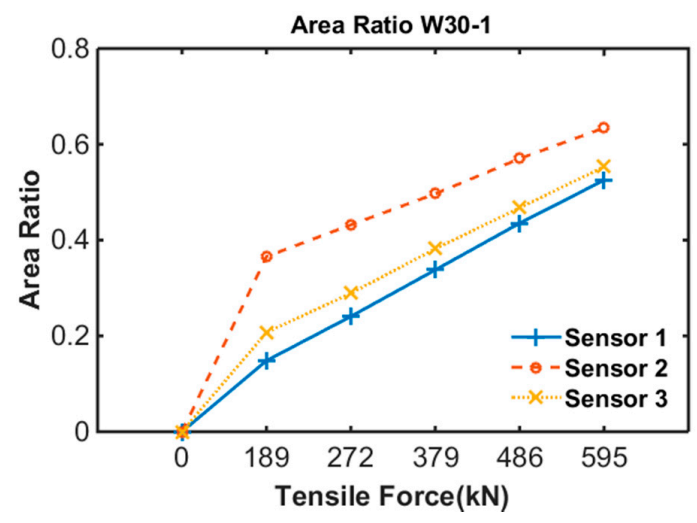

Figure 11. Area ratio of specimen 1.

Figure 12 shows the result of the area ratio calculation from the area of the B-H loop of specimen 2. The result shows a similar pattern to that of the result of specimen 1. However, friction loss was observed with the sensors because of the curved sheath of specimen 2 .

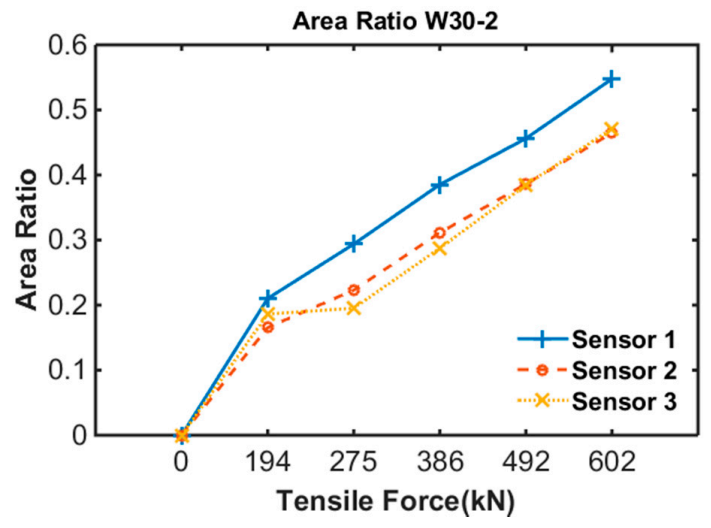

Figure 12. Area ratio of specimen 2.

Figure 13 shows the relationship between area ratio of Sensor no. 1 of each specimen and reference tensile force measured by the load cell at the left side of each specimen. As shown in the figure, the area ratio and tensile force had a linear relationship, and the tensile force of a PSC girder can be estimated using Equation (2).

$$
\text { Tensile Force }(k N)=1065 \times A_{r}
$$

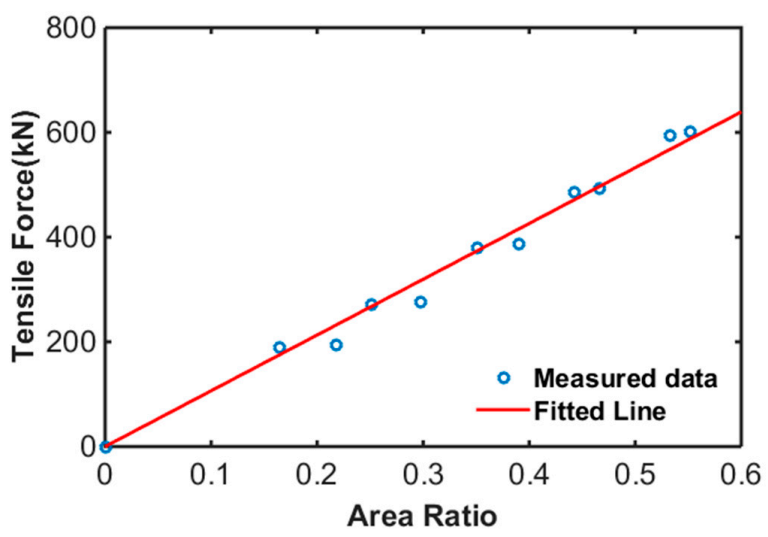

Figure 13. Relationship between area ratio and reference stress. 
According to the results, the embedded EM sensors could estimate the tensile forces in PS tendons with acceptable error by tracking the area ratio variations. Furthermore, the friction losses and the tensile force distribution in the PS tendons could be monitored using the embedded EM sensor.

\section{Conclusions}

An embedded EM sensor based tensile force monitoring for PSC girders was proposed in this research. The B-H loop of ferromagnetic material is affected by the induced tensile force in the specimen. To measure the B-H loop of PS tendons in a PSC girder, an embedded EM sensor was developed as a sheath joint. To validate the proposed method, a down-scaled PSC girder test was performed using two PSC girder specimens that had 1 sheath line in each specimen. The embedded EM sensors were installed at the left and right anchorage parts and the maximum eccentric part through the sheath before casting concrete. After casting and curing concrete, tensile force was induced in steps, and the B-H loop was measured at every tensile force step. Also, the reference tensile forces were measured from the load cell at the left anchorage of each specimen. The area of the B-H loop decreased with tensile force increase. To quantify the area variation, the area ratio was calculated, and the equation for estimating tensile force was derived by comparing the area ratio and reference tensile force. According to the results, the embedded EM sensor can measure the magnetic responses of unrevealed PS tendon even if it located inside of concrete and the tensile force could be estimated based on the area ratio variations of the PS tendon using the embedded EM sensors in the field environment.

Acknowledgments: This research was supported by a grant (14CTAP-C078424-01\#) from the Infrastructure and Transportation Technology Promotion Research Program funded by the Ministry of Land, Infrastructure, and Transport of Korean government, the Development of Design and Construction Technology for Double Deck Tunnel in Great Depth Underground Space (14SCIP-B088624-01) from the Construction Technology Research Program funded by the Ministry of Land, Infrastructure and Transport of Korean government, a grant (2017-MPSS31-001) from the Supporting Technology Development Program for Disaster Management funded by the Ministry of Public Safety and Security (MPSS) of the Korean government, and the National Research Foundation of Korea (NRF) grant funded by the Korean government (MSIP) (No. NRF-2017R1A2B3007607, NRF-2017-R1D1A1B03033399, NRF-2014R1A2A1A11054299).

Author Contributions: Junkyeong Kim and Ju-Won Kim conceived and designed the experiments; Junkyeong Kim performed the experiments; Junkyeong Kim and Changgil Lee analyzed the data; Junkyeong Kim and Seunghee Park wrote the paper. In addition, Junkyeong Kim and Seunghee Park are responsible for the implementation the proposed scheme.

Conflicts of Interest: The authors declare no conflict of interest.

\section{References}

1. Rens, K.L.; Wipf, T.J.; Klaiber, F.W. Review of nondestructive evaluation techniques of civil infrastructure. J. Perform. Const. Facil. 1997, 11, 152-160. [CrossRef]

2. Kim, J.W.; Kim, J.; Park, S.; Oh, T.K. Integrating embedded piezoelectric sensors with continuous wavelet transforms for real-time concrete curing strength monitoring. Struct. Infrastruct. E 2015, 11, 897-903. [CrossRef]

3. Lee, C.; Kim, J.; Park, S.; Kim, D.H. Advanced Fatigue Crack Detection using Nonlinear Self-Sensing Impedance Technique for Automated NDE of Metallic Structures. Res. Nondestruct. Eval. 2015, 26, 107-121. [CrossRef]

4. Lee, C.; Park, S. Damage visualization of pipeline structures using laser-induced ultrasonic waves. Struct. Health Monit. 2015, 14, 475-488. [CrossRef]

5. Lee, C.; Park, S. Flaw Imaging Technique for Plate-Like Structures Using Scanning Laser Source Actuation. Shock Vib. 2014, 725030. [CrossRef]

6. Lee, C.; Kang, D.; Park, S. Visualization of Fatigue Cracks at Structural Members using a Pulsed Laser Scanning System. Res. Nondestruct. Eval. 2015, 26, 123-132. [CrossRef]

7. Park, S.; Kim, J.W.; Lee, C.; Lee, J.J. Magnetic Flux Leakage Sensing-Based Steel Cable NDE Technique. Shock Vib. 2014, 929341. [CrossRef] 
8. Weiher, H.; Zilch, K. Condition of post-tensioned concrete bridges-assessment of the German stock by a spot survey of damages. In Proceedings of the First International Conference on Advances in Bridge Engineering, London, UK, 26-28 June 2006; Brunel University: London, UK, 2006; pp. 26-28.

9. Youn, S.G.; Kim, E.K. Deterioration of bonded post-tensioned concrete bridges and research topics on the strength evaluation in ISARC. In Proceedings of the JSCE-KSCE Joint Seminar on Maintenance and Management Strategy of Infrastructure in Japan and Korea, Shiga, Japan, 20 September 2006; Sakai, K., Ed.; JSCE: Tokyo, Japan, 2006; pp. 49-63.

10. Bruce, S.M.; McCarten, P.S.; Freitag, S.A.; Hasson, L.M. Deterioration of prestressed concrete bridge beams. In Land Transport New Zealand Research Report; Land Transport New Zealand: Wellington, New Zealand, 2008; Volume 337, p. 72.

11. Shenoy, C.V.; Frantz, G.C. Structural tests of 27-year-old prestressed concrete bridge beams. PCI J. 1991, 36, 80-90. [CrossRef]

12. Aalami, B.O. Time-dependent analysis of post-tensioned concrete structures. Prog. Struct. Eng. Mater. 1998, 1, 384-391. [CrossRef]

13. Pantelides, C.P.; Saxey, B.W.; Reaveley, L.D. Posttensioned tendon losses in a spliced-girder bridge, Part 1: Field measurements. PCI J. 2007, 52, 1-15.

14. Lakshmanan, N.; Saibabu, S.; Murthy, A.R.C.; Ganapathi, S.C.; Jayaraman, R. Experimental, numerical and analytical studies on a novel external prestressing technique for concrete structural components. Comput. Concr. 2009, 6, 41-57. [CrossRef]

15. Im, S.; Hurlebaus, S.; Trejo, D. Inspections of voids in external post-tensioned tendons. In Transportation Research Board; Business Office: Washington, DC, USA, 2010.

16. Onyemelukwe, O.; Kunnath, S. Field Measurement and Evaluation of Time-Dependent Losses in Prestressed Concrete Bridges; Research Report: Project Number: WPI-0510735; Florida Department of Transportation: Tallahassee, FL, USA, 1997.

17. Chen, H.L.; Wissawapaisal, K. Measurement of tensile forces in a seven-wire prestressing strands using stress waves. J. Eng. Mech. 2001, 127, 599-606. [CrossRef]

18. Washer, G.A.; Green, R.E.; Pond, R.B. Velocity constants for ultrasonic stress measurement in prestressing tendons. Res. Nondestruct. Eval. 2002, 14, 81-94. [CrossRef]

19. Kim, J.T.; Yun, C.B.; Ryu, Y.S.; Cho, H.M. Identification of prestress-loss in PSC beams using modal information. Struct. Eng. Mech. 2003, 17, 467-482. [CrossRef]

20. Kim, J.T.; Park, J.H.; Hong, D.S.; Cho, H.M.; Na, W.B.; Yi, J.H. Vibration and impedance monitoring for prestress-loss prediction in PSC girder bridges. Smart Struct. Syst. 2009, 5, 81-94. [CrossRef]

21. Kim, J.M.; Kim, H.W.; Park, Y.H.; Yang, I.H.; Kim, Y.S. FBG sensors encapsulated into 7-wire steel strand for tension monitoring of a prestressing tendon. Adv. Struct. Eng. 2012, 15, 907-917. [CrossRef]

22. Lan, C.; Zhou, Z.; Ou, J. Monitoring of structural prestress loss in RC beams by inner distributed brillouin and fiber Bragg grating sensors on a single optical fiber. Struct. Control Health Monit. 2014, 21, 317-330. [CrossRef]

23. Duan, Y.F.; Zhang, R.; Zhao, Y.; Or, S.W.; Fan, K.Q.; Tang, Z.F. Smart elasto-magneto-electric (EME) sensors for stress monitoring of steel structures in railway infrastructures. J. Zhejiang Univ.-Sci. A 2011, 12, 895-901. [CrossRef]

24. Cho, S.; Yim, J.; Shin, S.W.; Jung, H.; Yun, C.; Wang, M.L. Comparative Field Study of Cable Tension Measurement for a Cable-Stayed Bridge. J. Bridg. Eng. 2012, 18, 748-757. [CrossRef]

25. Zhao, Y.; Wang, M.L. Fast EM stress sensors for large steel cables. In Proceedings of the SPIE 6934, Nondestructive Characterization for Composite Materials, Aerospace Engineering, Civil Infrastructure, and Homeland Security 2008, San Diego, CA, USA, 9 March 2008.

26. Wang, M.L.; Chen, Z.; Koontz, S.S.; Lloyd, G.D. Magneto-elastic permeability measurement for stress monitoring. In Proceedings of the SPIE 7th Annual Symposium on Smart Structures and Materials, Health Monitoring of the Highway Transportation Infrastructure, Newport Beach, CA, USA, 6-9 March 2000; Volume 3995, pp. 492-500.

27. Holst, A.; Wichmann, H.-J.; Hariri, K.; Budelmann, H. Monitoring of tension members of civil structures-New concepts and testing. In Proceedings of the 3rd European workshop on SHM 2006, Granada, Spain, 5-7 July 2006; pp. 117-125. 
28. Joh, C.; Lee, J.W.; Kwahk, I. Feasibility study of stress measurement in prestressing tendons using Villari effect and induced magnetic field. Int. J. Distrib. Sens. Netw. 2013, 9, 1-8. [CrossRef]

29. Duan, Y.F.; Zhang, R.; Zhao, Y.; Or, S.W.; Fan, K.Q. Steel stress monitoring sensor based on elasto-magnetic effect and using magneto-electric laminated composite. J. Appl. Phys. 2012, 111, 07E516. [CrossRef] 